\title{
DESIGN OF A PLANAR UWB ANTENNA WITH BAND REJECTION
}

\author{
YASSER A. FADHEL AND BAYEZ K. AL-SULAIFANIE
}

Dept. of Electrical and Computer Engineering, University of Duhok.

\begin{abstract}
This paper is oriented on the design of a planar Ultra-Wideband (UWB) antenna covering the entire UWB frequency range with band-rejection of $(5.18$ - $6.10 \mathrm{GHz})$ to avoid the interference with other existing wireless communication systems like WLAN and WiMAX. The band-rejection has been performed by adding a slit to the circular radiating patch transversely to the direction of current flow with a length tuned to the effective half-wavelength which is opposite to the center of rejected band $(5.5 \mathrm{GHz})$. The length of the added slit has been chosen according to a suggested formula unlike other previous works done by trial and error method. CST software package has been used to simulate the designed antenna. Simulation results have shown that this antenna obeys the UWB requirements with a reduction in its gain at the rejection band. Practical implementation has also been performed and measurements confirm the design and simulation results.
\end{abstract}

KEYWORDS :- UWB Antenna; Band Rejection; PCMA; Microstrip Antenna.

\section{INTRODUCTION}

Qince regulations for UWB frequency range Whas been confirmed by the Federal Communication Commission (FCC) in 2002 [1], researchers started to design different communication systems working at different field like; data transmission, industrial applications, medical instruments, military and security applications, etc. The wireless transmission for UWB signals won't be done without powerful antennas working on the frequency range (3.1 10.6 GHz). Although UWB antennas are designed to cover a very wide range of frequencies [2] [3], but in the same time the interference with other existing wireless communication systems is possible. Therefore many of these UWB antennas are designed to cover the entire UWB frequency range with rejection at some frequency bands being used by other existing wireless technologies such as WLAN (5.15-5.82 GHz) WiMAX (5.25$5.82 \mathrm{GHz}$ ) [4]. Different techniques have been used by researchers to design such antennas. In [5] a dual band rejection has been performed via etching split ring slot and S-shaped slot. Another design by [6] was used a C-shaped slit added to an elliptical shape monopole and a pair of $\lambda / 4$ resonator centered around the microstrip line. This configuration is preventing interferences with WLAN and WiMAX wireless technologies. The C-shaped annular ring slot with half wavelength has also been used by [7] to prevent interference with WLAN frequencies (5.1-5.9 GHz). Spurlines have been embedded on the ground plane of circular monopole to reject a band of frequencies from $4.7 \mathrm{GHz}$ to $5.9 \mathrm{GHz}$ [8].

One of the powerful techniques for band rejection is performed via adding the complementary split ring resonators (CSRRs) with different shapes and sizes. Two identical square (CSRRs) have been etched from the radiating patch to reject interfering with WLAN and WiMAX technologies [9]. In other work, rectangular CSRRs have been added to a circular planar monopole antenna that rejected the 5.5 GHz WLAN band [10]. 
A slit has been added to an elliptical microstrip antenna to cut unwanted areas, at which it is supposed to have no current distribution being exist. This technique has been merely used without getting benefit from its ability in rejection of some frequencies [11]. Therefore this paper is oriented on the using of such slit in designing a planar circular monopole antenna (PCMA) to reject certain frequency band while covering the other UWB frequency range. The length of this slit will be chosen to be equal to the half wave length of the center frequency of the rejected band. Simulation has been done by CST Microwave Studio 2014. Then practical implementation on FR4 PCB boards has been performed and some experimental measurements have been taken via Rohde \& Schwarz ${ }^{\circledR}$ ZVL13 Vector Network Analyzer which validates the simulation results.

\section{ANTENNA DESIGN}

A planar circular monopole antenna (PCMA) has been used as UWB antenna. This antenna is simple and it is most commonly used for UWB frequency band in addition to its miniature size. The geometry of this antenna is illustrated in Fig. 1 (a). It has been simulated using a dielectric FR4 substrate of $1.6 \mathrm{~mm}$ thickness, relative permittivity of 4.3 , and dielectric loss tangent of 0.025 .

The lower band-edge frequency $f_{L}$ (first resonant frequency) is determined by the diameter of the disc which is about 0.25 of $\lambda$ in air [12], or it could be determined using the formula suggested in [13]:

$$
f_{L}=\frac{c}{\lambda}=\frac{7.2}{(L+r+P) * k} G H z
$$

Where the values of $r$ and $L$ are of the equivalent cylindrical monopole antenna for PCMA with a radius of $R$, and they are given by [13] as:

$$
\begin{aligned}
& L=2 R \\
& r=\frac{R}{4}
\end{aligned}
$$

While $P$ is the length of the $50 \Omega$ feed line in $\mathrm{cm}$ between the ground plane and the radiator, which it has been optimized to $0.75 \mathrm{~mm}$ by trial and error for this design, and $k=\sqrt{\varepsilon_{e f f}}$. The approximated value of $\varepsilon_{e f f}$ is given by [14]:

$$
\varepsilon_{\text {eff }} \approx \frac{\varepsilon_{r}+1}{2}
$$

If FR4 substrate having a thickness of $1.6 \mathrm{~mm}$ is used, then equation (4) gives $\varepsilon_{\text {eff }}=2.65$, and accordingly $k$ will be 1.627 . This value was empirically determined to be equal to 1.15 by [15]. Therefore if the lower frequency is chosen to be $3.1 \mathrm{GHz}$, then $\mathrm{R}=10.5 \mathrm{~mm}$. To ensure that the lower frequency is less than $3.1 \mathrm{GHz}$ the disc radius $\mathrm{R}$ has been chosen to be $12.5 \mathrm{~mm}$. 

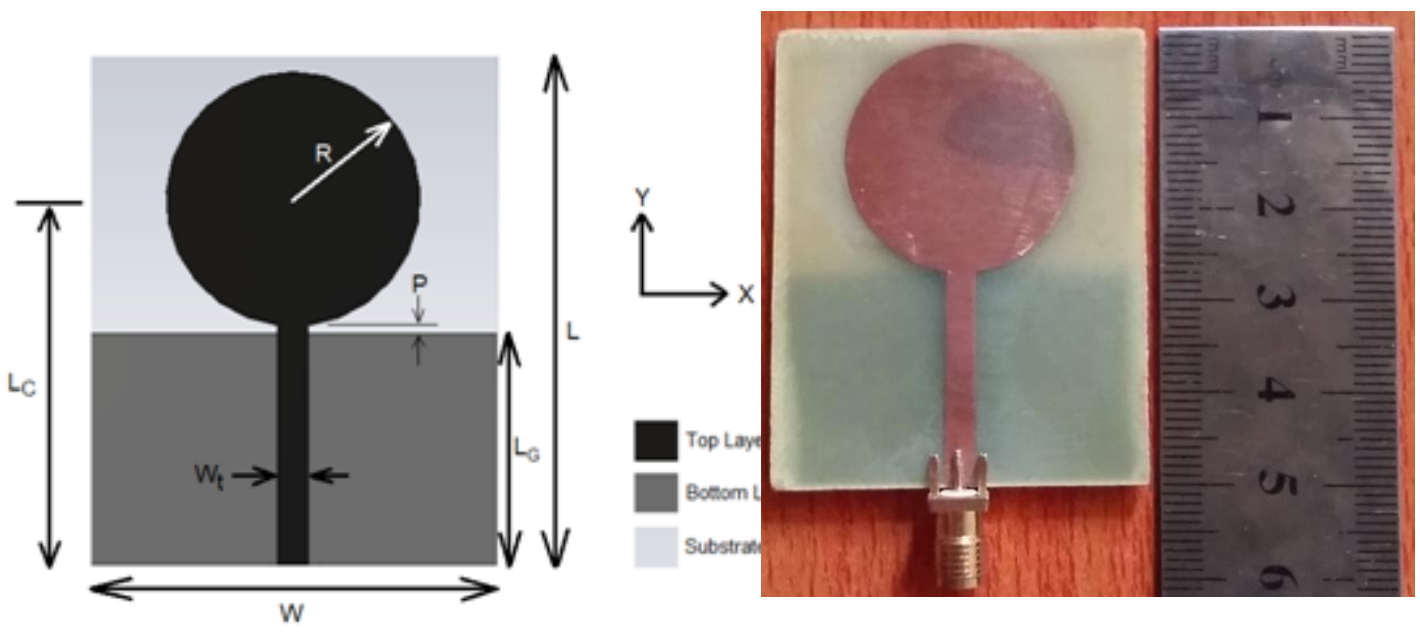

(a)

(b)

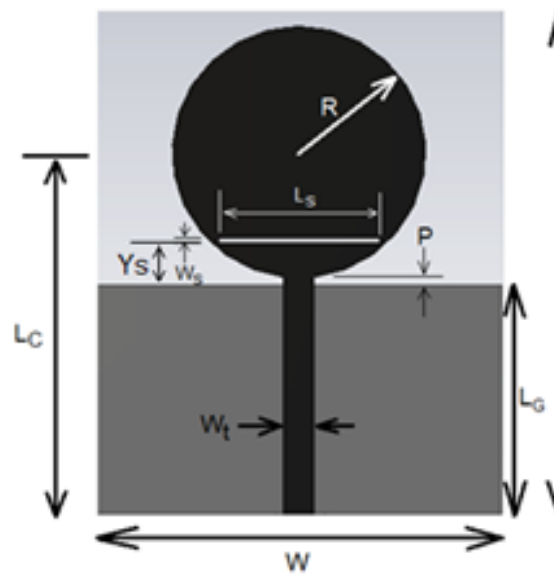

(c)

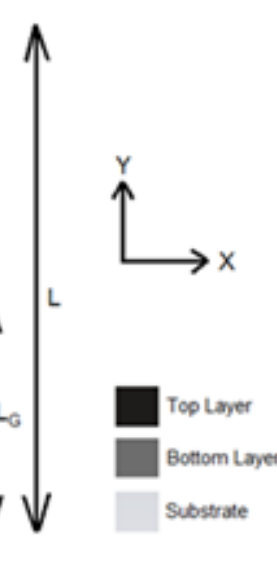

(d)

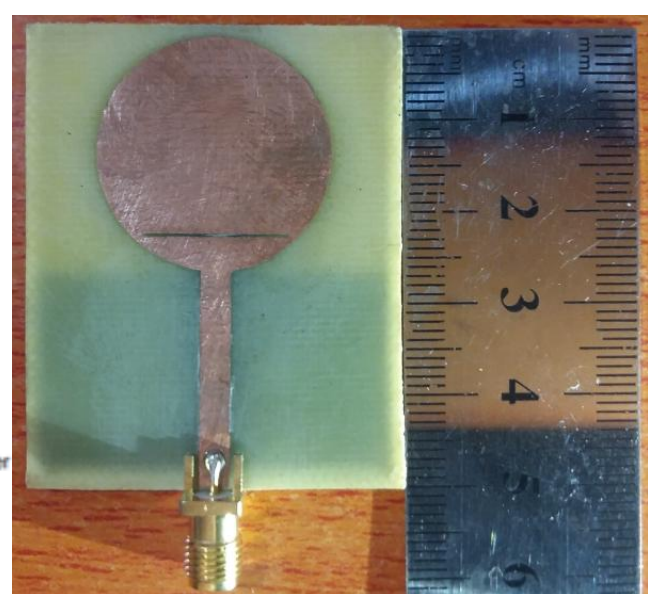

Fig.(1):- Design Geometry of (a) Simulated PCMA antenna, (b) Fabricated PCMA antenna, (c) Simulated PCMA antenna with band rejection and (d) Fabricated PCMA antenna with band rejection.

The width of the microstrip feed line $W_{t}$ has been calculated from the following equation $[16,17]$ :

$$
Z_{o}=\frac{87}{\sqrt{\varepsilon_{r}+1.41}} \ln \left(\frac{5.98 h}{0.8 W_{\text {StrL }}+t}\right)
$$

Where $Z_{o}$ is the characteristic impedance of the microstrip feed line, $h$ is the thickness of substrate which has been taken $1.6 \mathrm{~mm}$ as a typical value, $t$ is the metallization thickness which is taken as $0.035 \mathrm{~mm}, W_{S t r L}$ is the microstrip feed line width, and $\varepsilon_{r}$ for FR4 substrate is 4.3. Therefore, according to the above equation, for characteristic impedance of $50 \Omega$, $W_{\text {StrL }}$ must be set equal to $3 \mathrm{~mm}$, and for simplicity $W_{S t r L}$ has been named $W_{t}$ in Fig.1. The aforementioned and other design parameters are shown in the Table 1.

To add a band rejection to the PCMA UWB antenna a horizontal slit has been added to the radiating circular patch transversely to the direction of current flow with length of $L_{S}$ which has been tuned to the length of effective halfwavelength at the center frequency of rejection band $(5.5 \mathrm{GHz})$, The length $L_{S}$ is calculated by the following equation: 


$$
\begin{gathered}
L_{S}=\frac{\lambda_{\text {eff. }}}{2} \\
L_{S}=\frac{c}{2 * f \sqrt{\varepsilon_{e f f}}}=\frac{3 * 10^{8}}{2 * 5.5 * 10^{9} * 1.627} \\
L_{S}=16.7 \mathrm{~mm}
\end{gathered}
$$

Simulation result shown that better value is $16 \mathrm{~mm}$ which is very close to that calculated above.

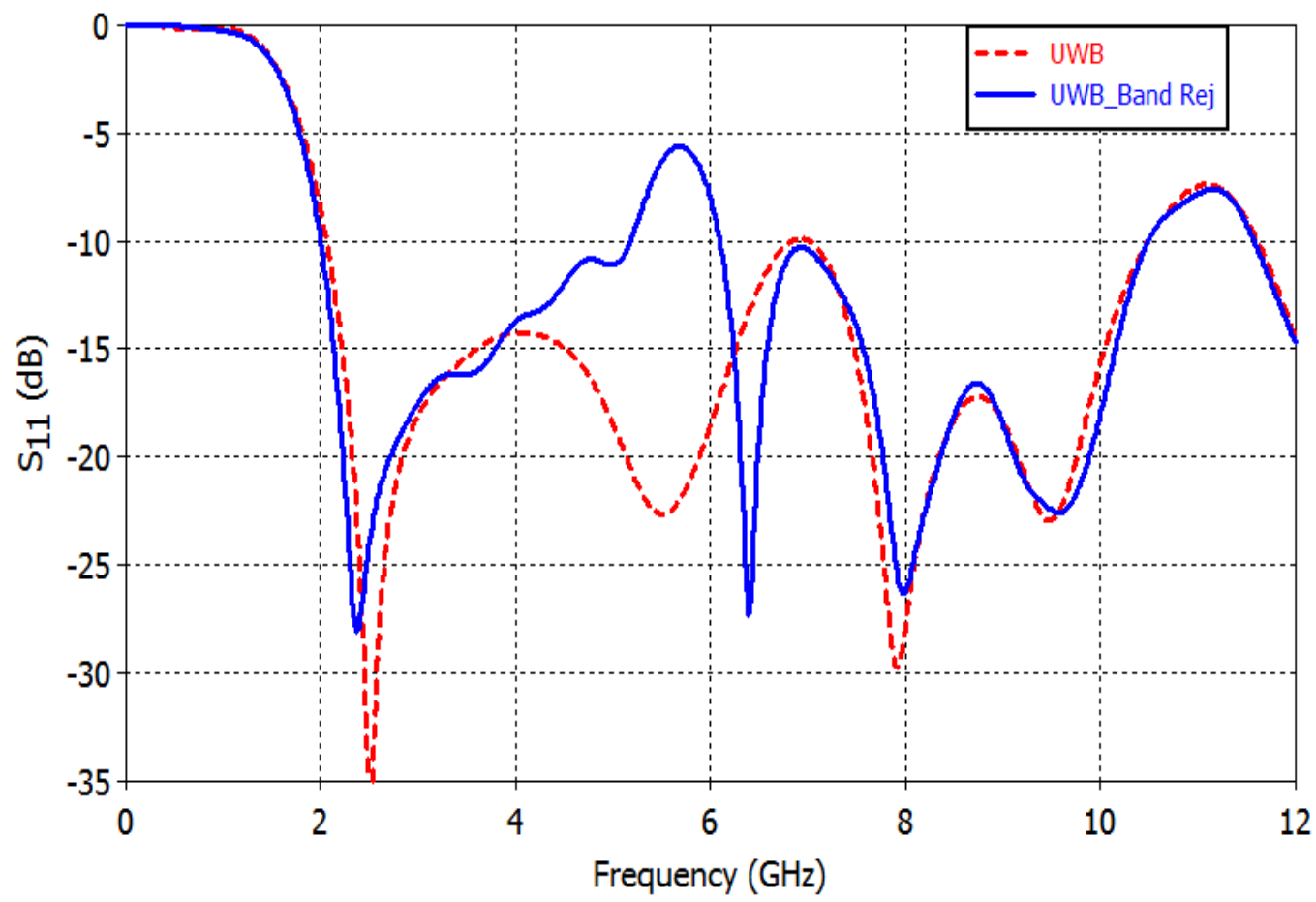

Fig.(2):- Return loss curves for both of PCMA UWB antenna and PCMA UWB antenna with band rejection. 


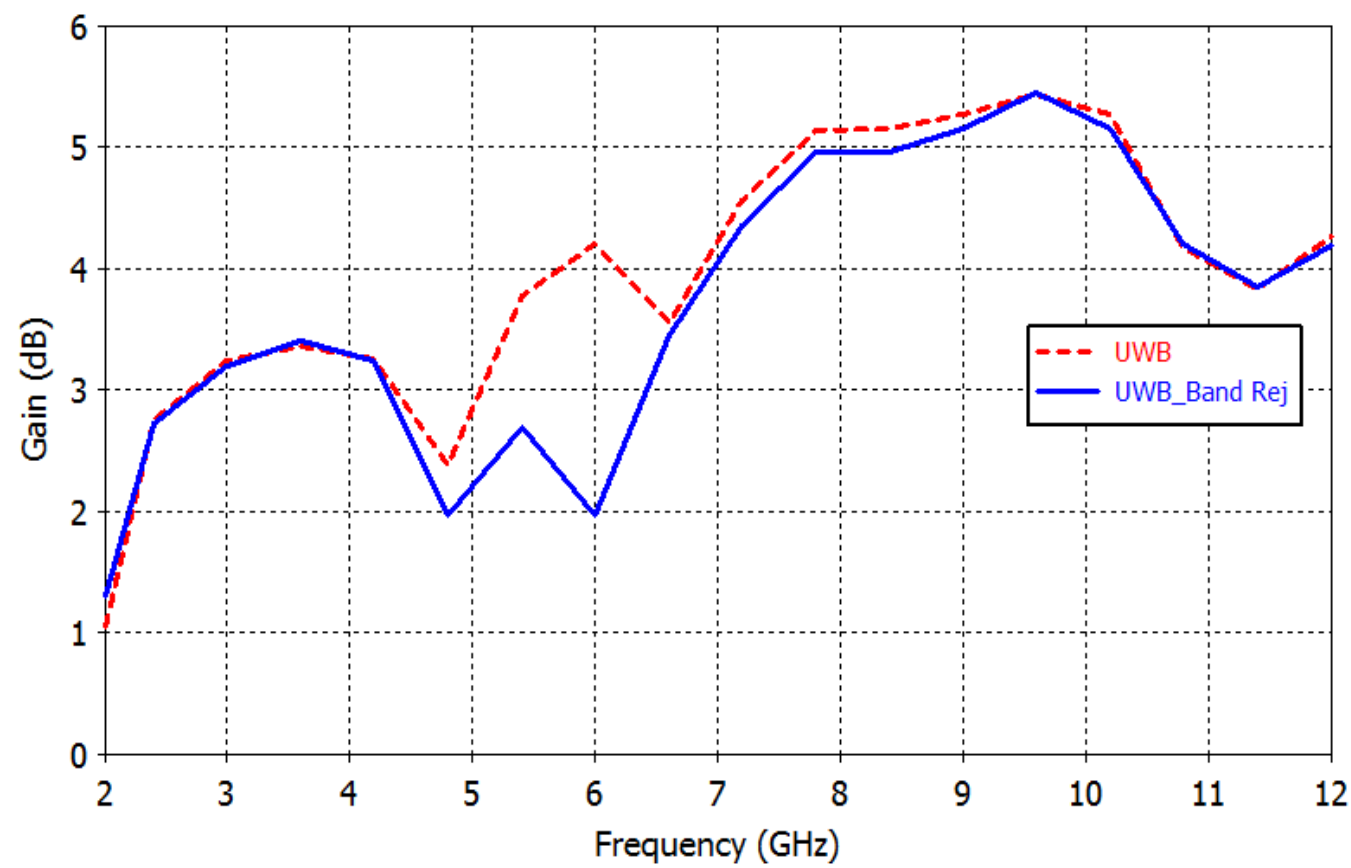

Fig.(3):- Gain curves for both of PCMA UWB antenna and PCMA UWB antenna with band rejection

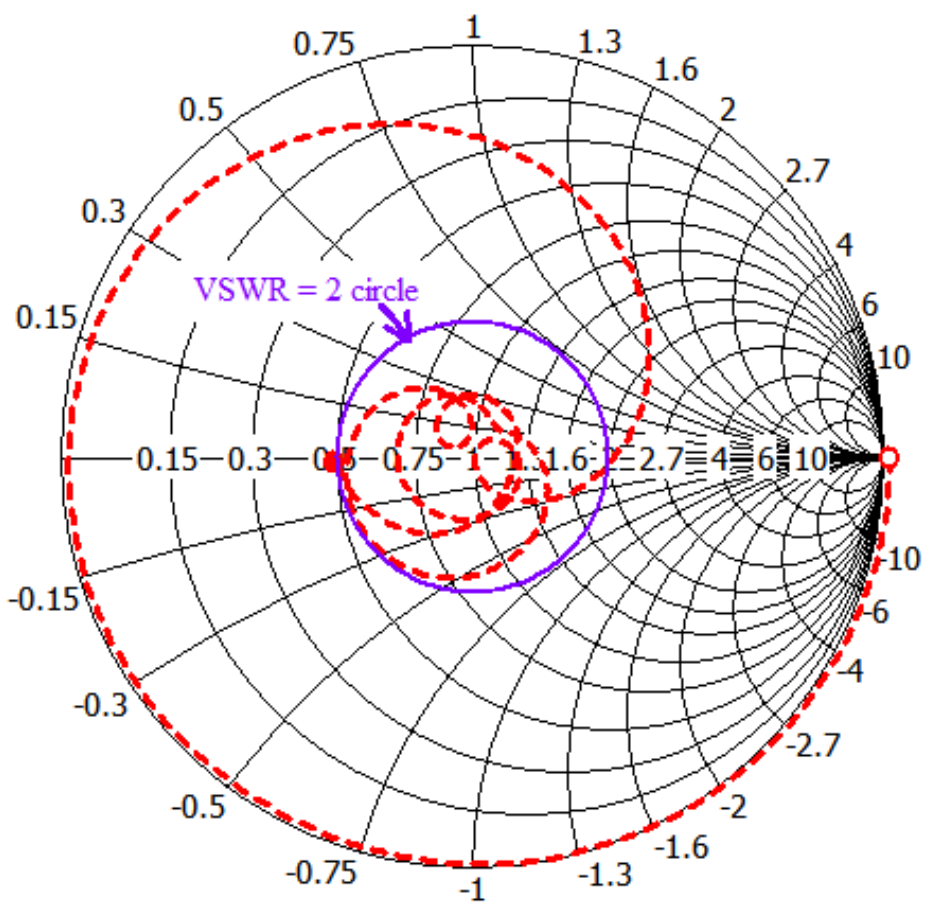

(a) 


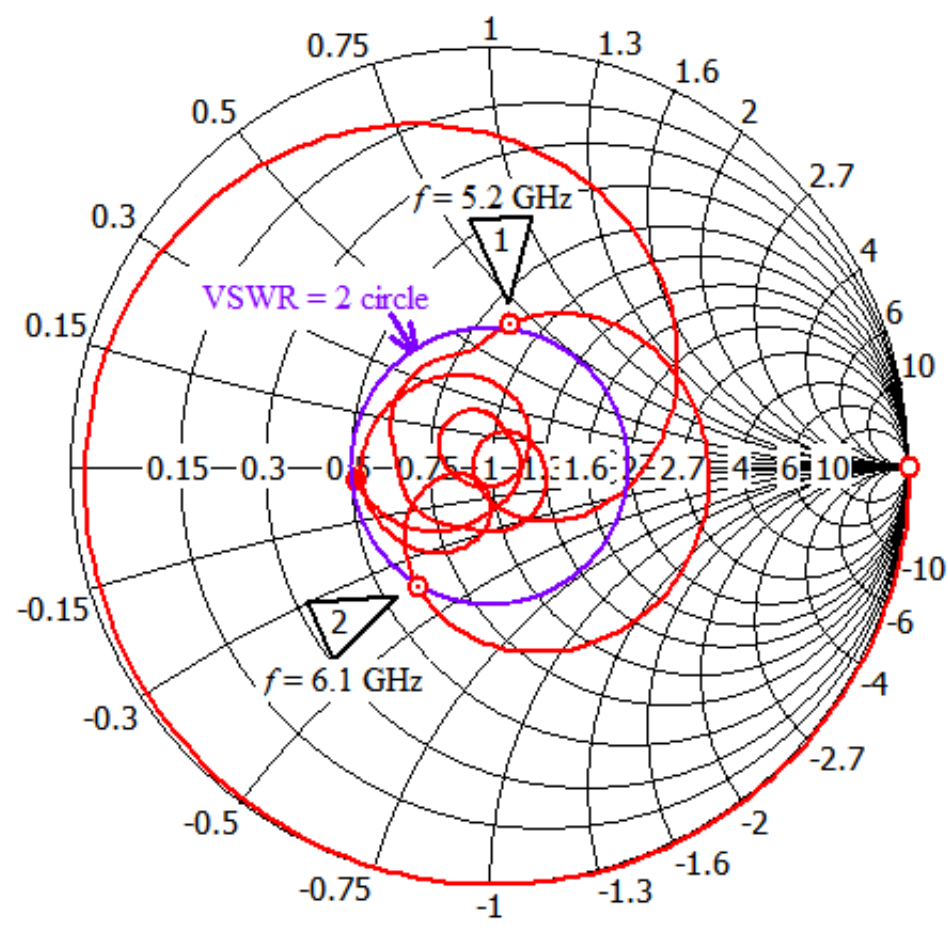

(b)

Fig.(4 ):-The Smith charts of (a) PCMA UWB antenna and (b) PCMA UWB antenna with band rejection
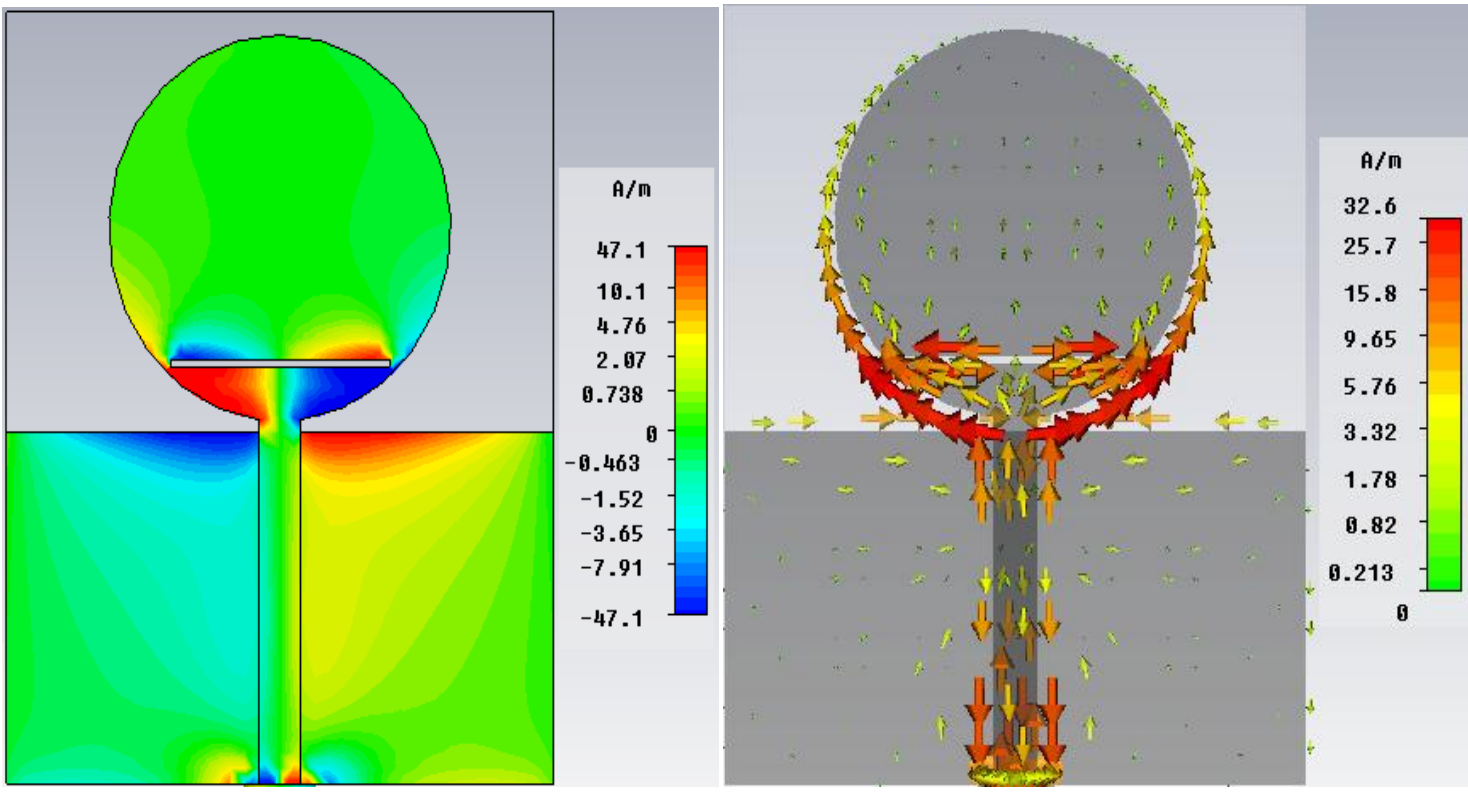

(a) 

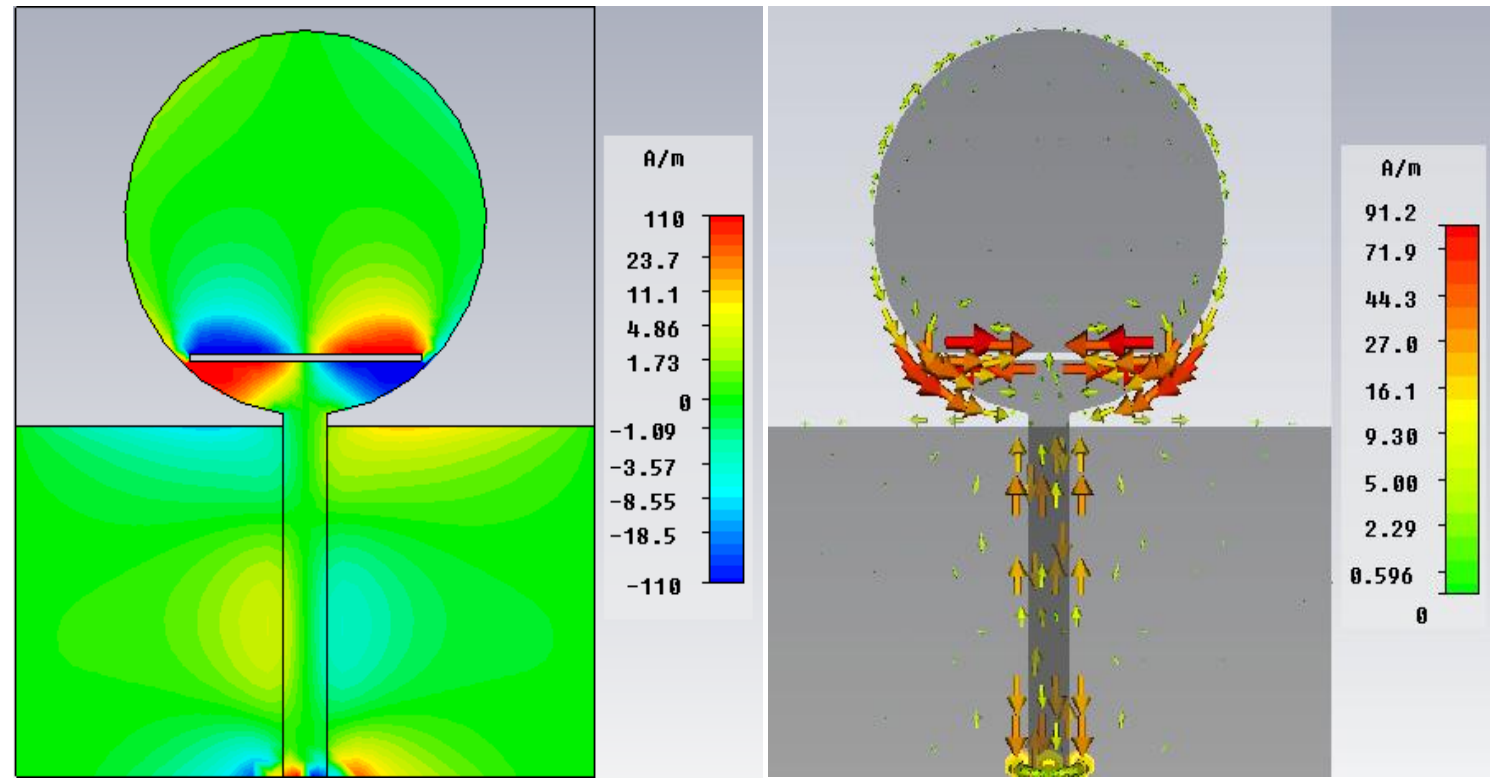

(b)

Fig.(5):- Surface current distribution PCMA UWB antenna with band rejection for (a) $3.5 \mathrm{GHz}$ and (b) $5.5 \mathrm{GHz}$. The left side is a contour plot while the right side is a vector plot.

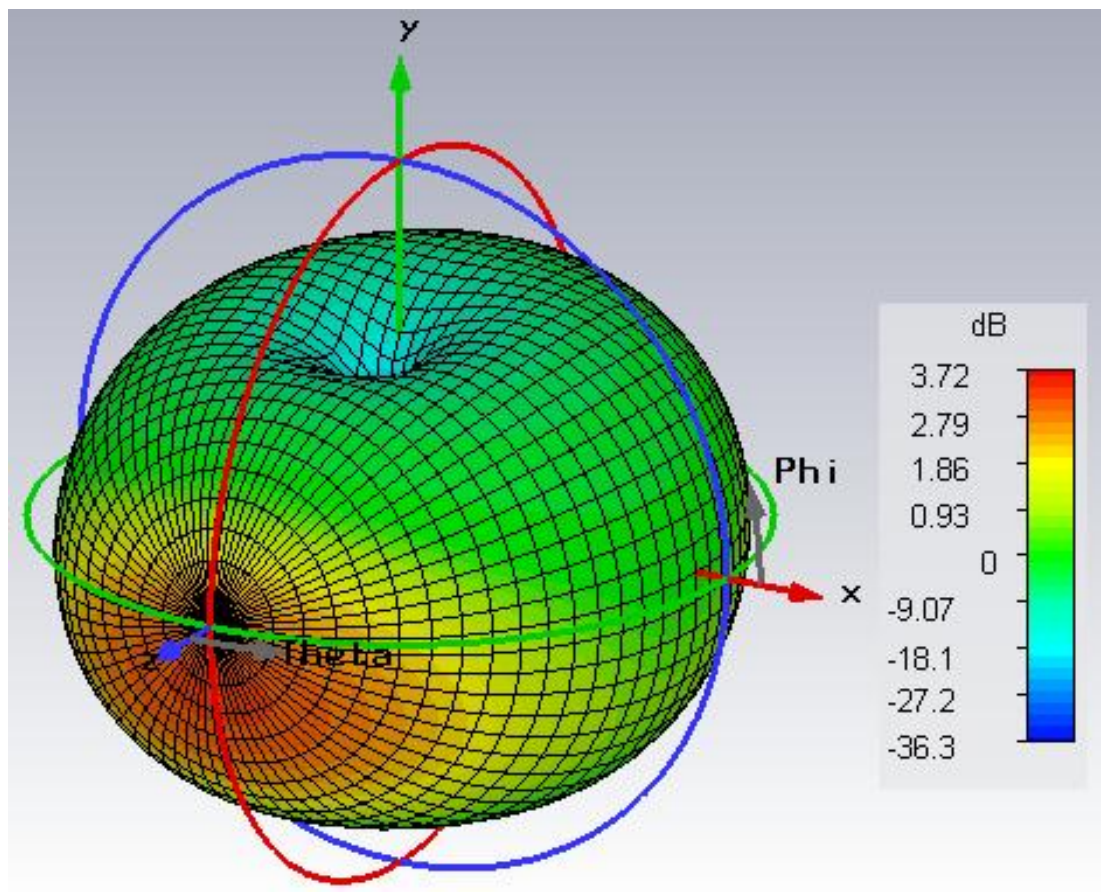

(a) 


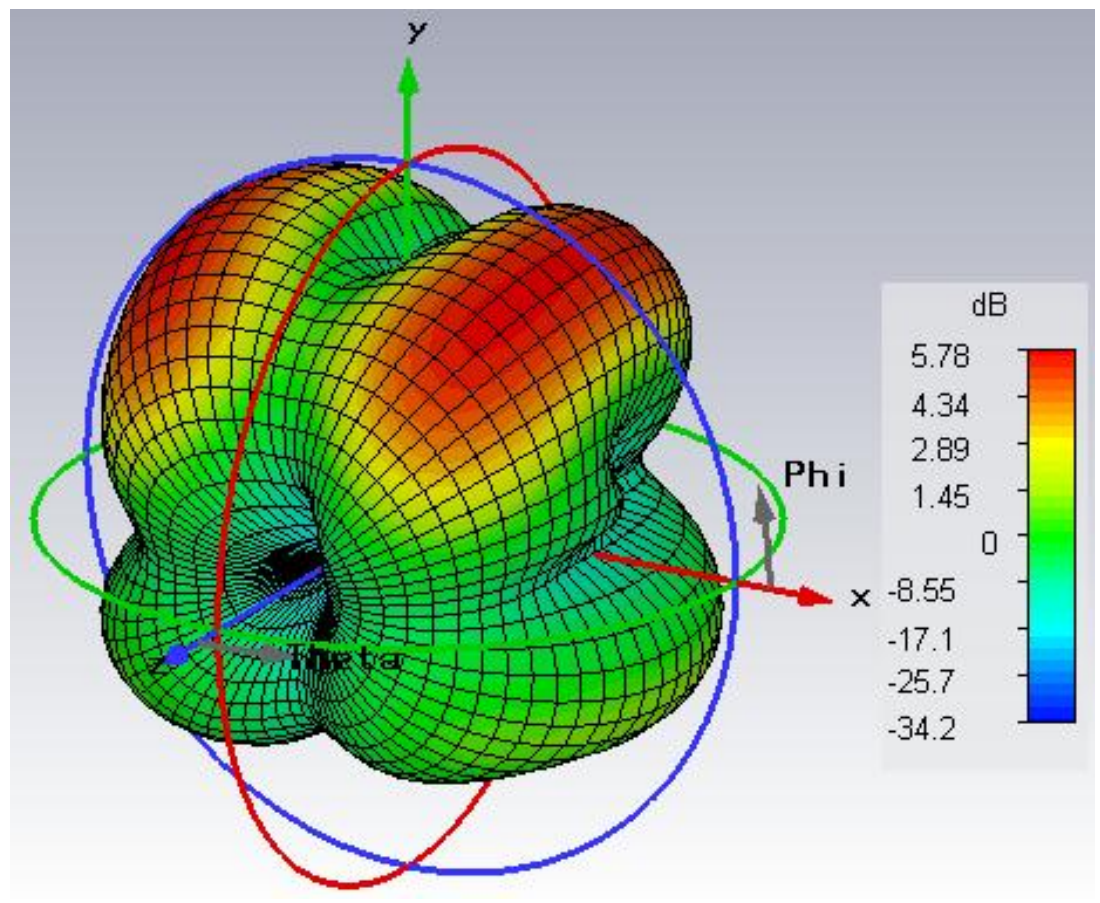

(b)

Fig.(6) :- Far-field pattern for PCMA UWB antenna at frequencies of; (a) $3.5 \mathrm{GHz}$ and (b) $8 \mathrm{GHz}$.

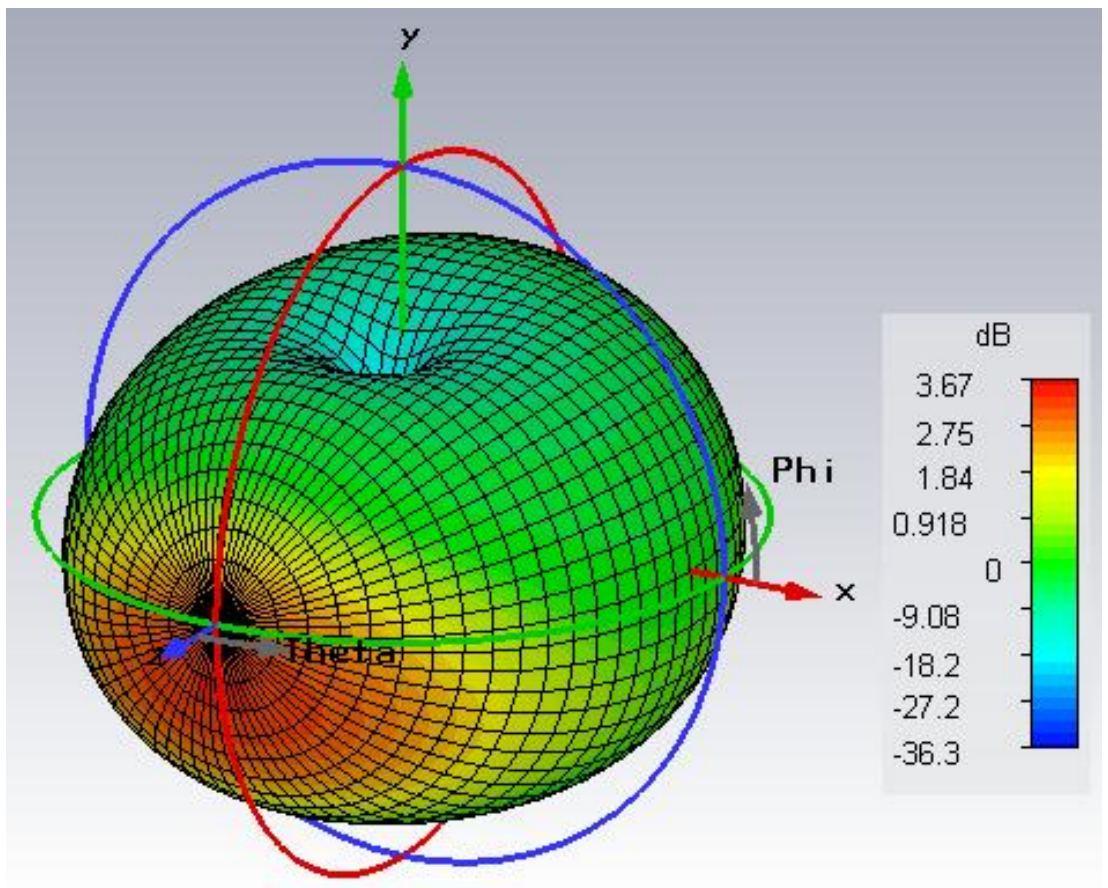

(a) 


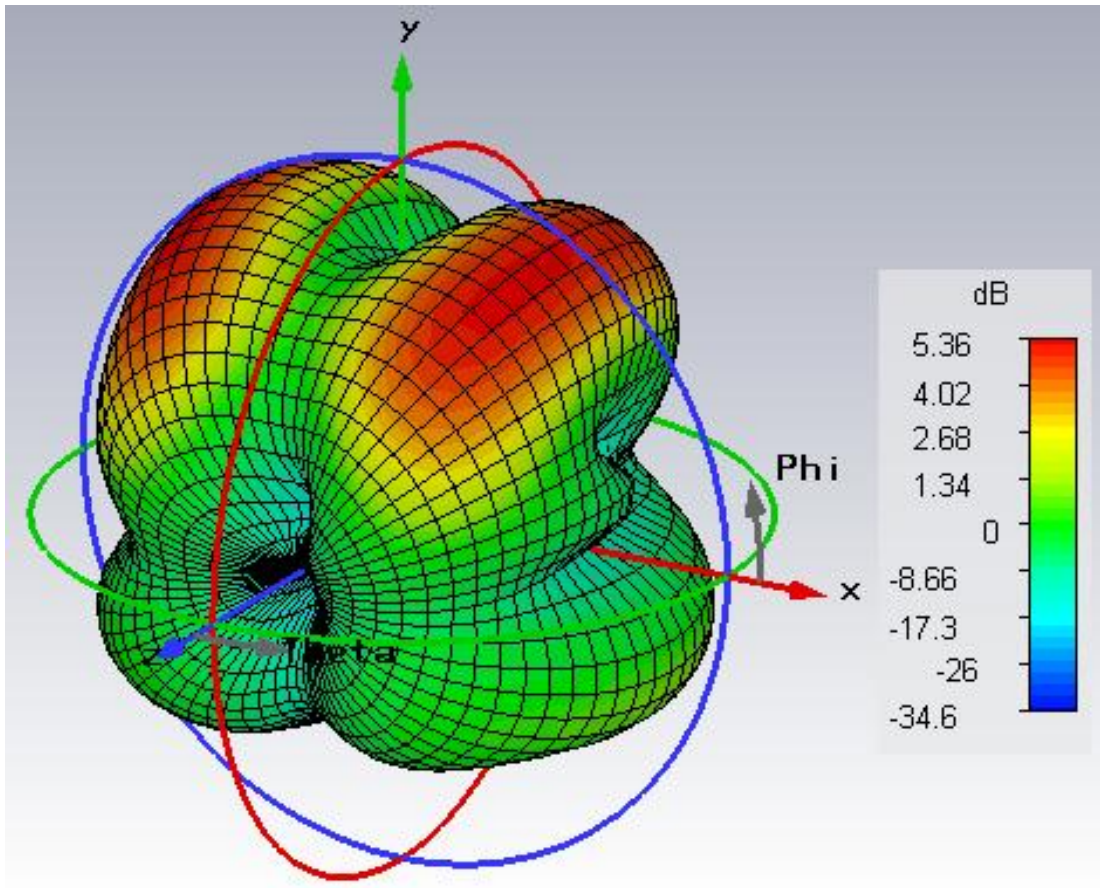

(b)

Fig.(7):-Far-field pattern for PCMA UWB antenna with band rejection at frequencies of; (a) $3.5 \mathrm{GHz}$ and (b) 8 GHz.



(a) 


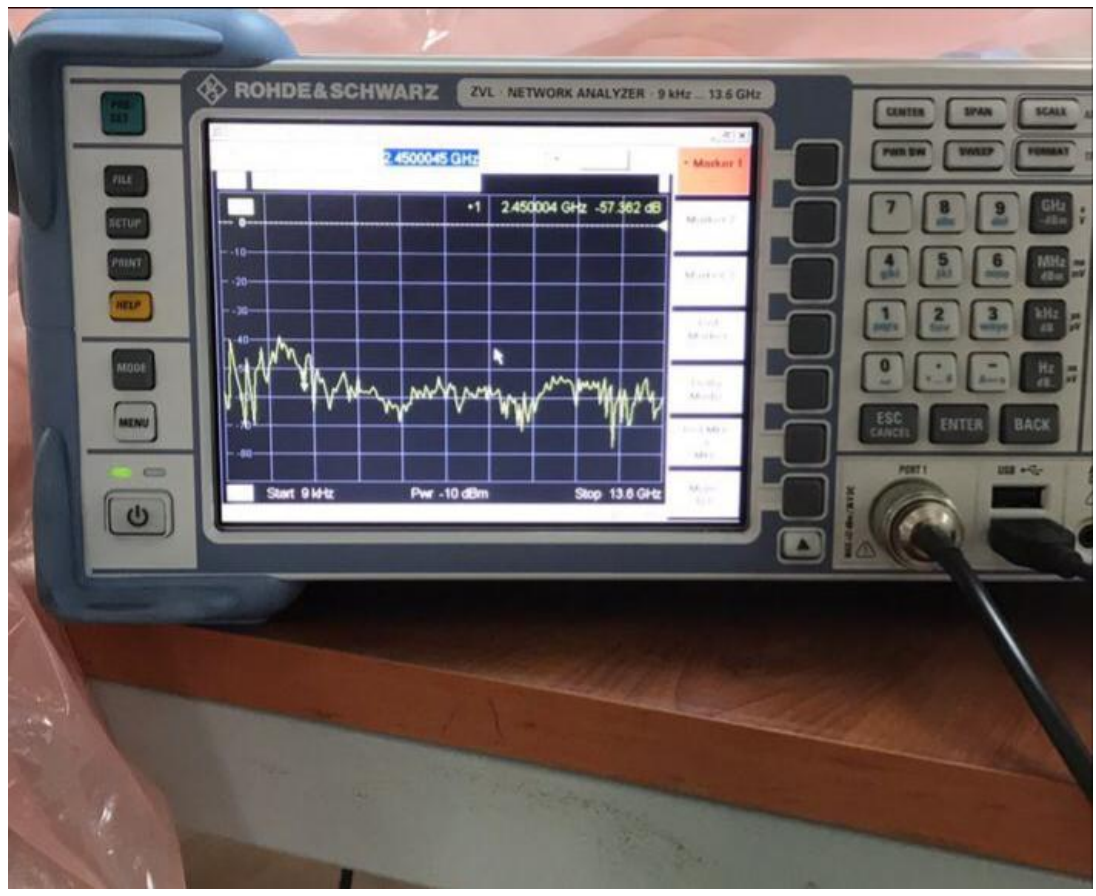

(b)

Fig.(8):- Measurement setup; (a) The turn table of testing the radiation pattern and (b) The Rohde \& Schwarz ${ }^{\circledR}$ ZVL13.

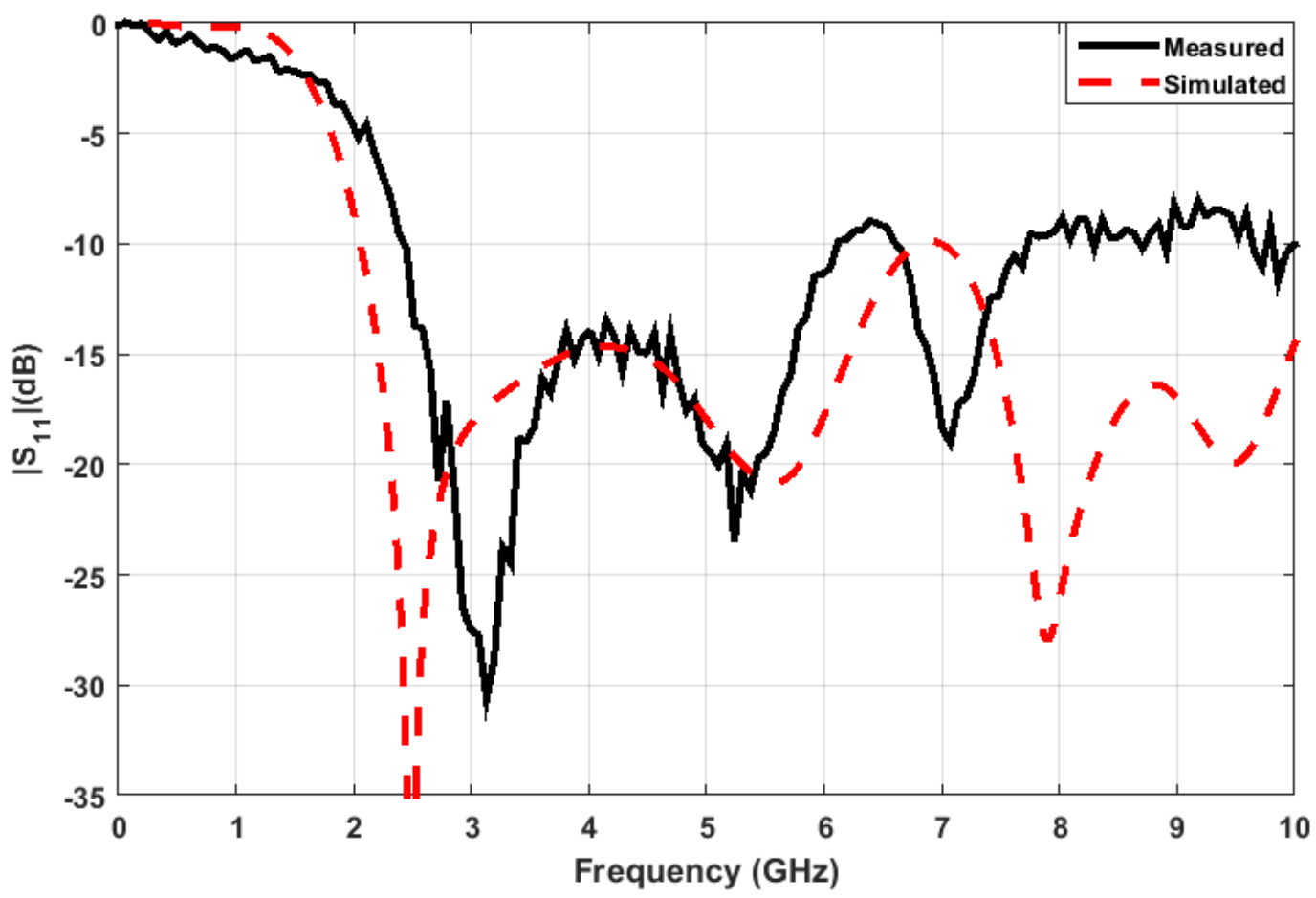

(a) 


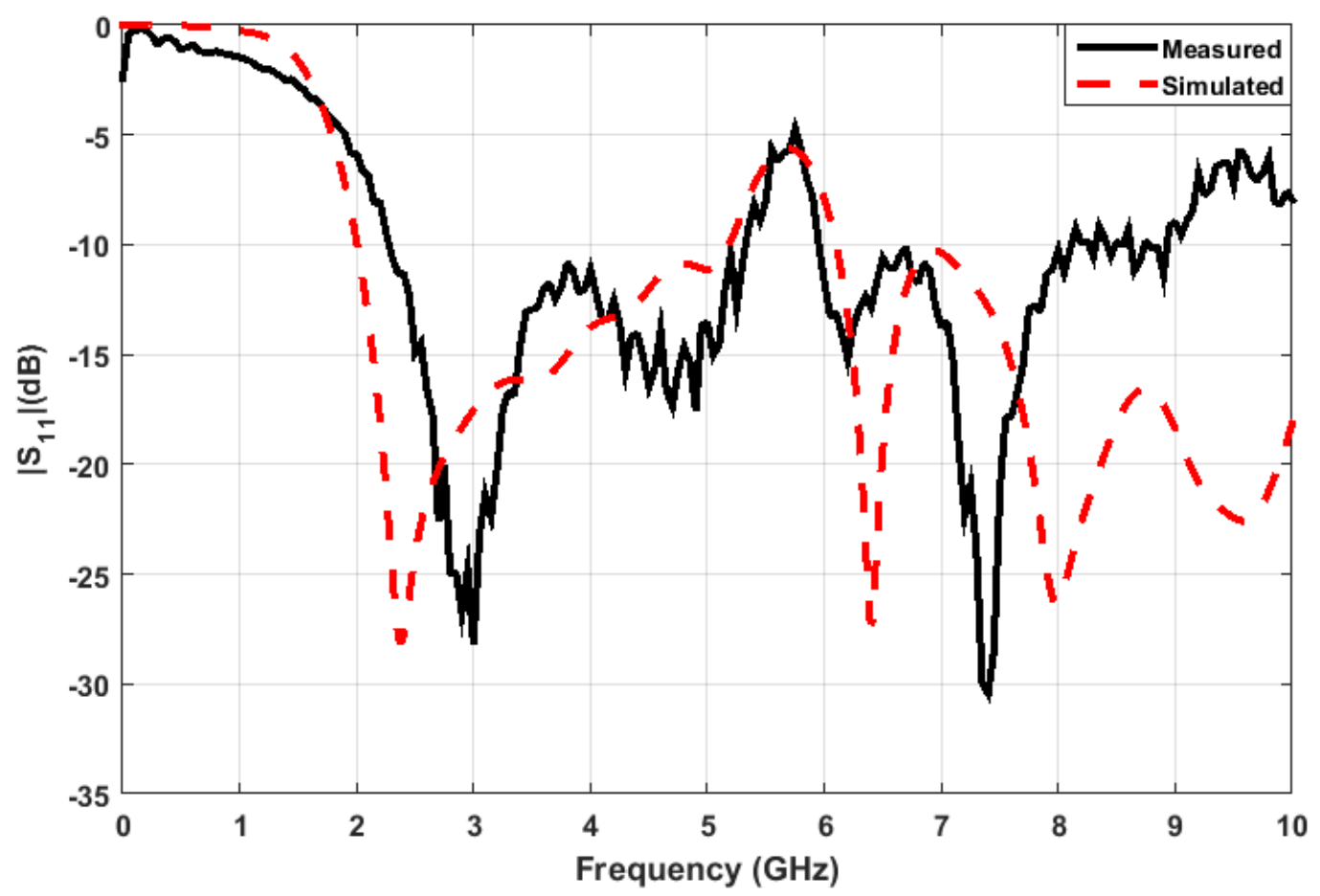

(b)

Fig.(9):- Measured Return loss curves for; (a) PCMA UWB antenna and (b) PCMA UWB antenna with band rejection.

\section{REFERENCES}

[1] First Report and Order (FCC 02-48). Action by the Commission Feb. 14, (2002). New public safety applications and broadband internet access among uses. envisioned by FCC authorization of Ultra-Wideband Technology.

[2] J. W. Jayasinghe and D. N. Uduwawala (2013), A novel miniature multi-frequency broadband patch antenna for WLAN applications. Proceedings of the IEEE $8^{\text {th }}$ International Conferences on Industrial and Information Systems (ICIIS '13), pp. 361-363, Peradeniya, Sri Lanka.

[3] Fadhel, Y. A., and, Sayidmarie, K. H. (2011), Selfcomplementary ring planer antenna of very wideband operation. Proceedings of ISAP2011, Jeju, Korea, 25-28 October.

[4] Sayidmarie, K. H., and Fadhel, Y. A. (2011), SelfComplementary Circular Disk Antenna for UWB Applications. Progress In
Electromagnetics Research C, 24, 111-122,.

[5] Thiripurasundari, D., and Emmanuel, D. S. (2013), Compact Dual Band-Reject UWB Antenna With Sharp Band-Edge Frequency. Progress In Electromagnetics Research Letters, 36, 41-55.

[6] Kim, S.-W., and Choi, D.-Y. (2016), Compact filtering monopole patch antenna with dual- band rejection. Springer Plus, 5, 883.

[7] Syed, A., and Aldhaheri, R. W. (2016), A Very Compact and Low Profile UWB Planar Antenna with WLAN Band Rejection. Hindawi Publishing Corporation, The Scientific World Journal. Art. ID 3560938.

[8] Lee, H. J., Jang, Y. H., and Choi, J. H. (2007), Design of an UWB Antenna with Band-rejection Characteristic. Progress In Electromagnetics Research Symposium (pp. 155-157). Prague, Czech Republic, 27-30 August.

[9] Lai, H.-Y., Lei, Z.-Y., Xie, Y.-J., Ning, G.-L., and Yang, K. (2011), UWB Antenna with Dual Band 
Rejection for WLAN/WIMAX Bands Using CSRRs. Progress In Electromagnetics Research Letters, 26, 69-78.

[10] Islam, M. M., Faruque, M. R. I., and Islam, M. T. (2014), A Compact $5.5 \mathrm{GHz}$ Band-Rejected UWB Antenna Using Complementary Split Ring Resonators. Hindawi Publishing Corporation, The Scientific World Journal. Art. ID 528489.

[11] Ali, M.T, Adznina, E. and Salleh, M. K. M., (2012), A Slotted Elliptical Antenna for Wideband Applications. Proceedings of ISAP2012, Nagoya, Japan, 25-28 October.

[12] Liang, J., Chiau, C., Chen, X., and Parini, C. (2005), Study of a printed circular disc monopole antenna for UWB systems. IEEE Transactions on Antennas and Propagation, Vol. 53, No. 11, 3500-3504.

[13] Ray, K. P. (2008), Design aspects of printed monopole antennas for UWB applications. Hindawi Publishing Corporation, International Journal of Antennas and Propagation, 8 pages.

[14] Balanis C. A. (2005). Antenna theory analysis and design (3rd ed.). John Wiley \& Sons Inc.

[15] Matin M. A. (2011), Ultra wideband communications: novel trends-antennas and propagation, InTech, Croatia, pp. 177-183, July.

[16] Wadell, B. C. (1991). Transmission line design handbook. Norwood, MA: Artech House, ISBN: 0-89006-436-9.

[17] Wheeler, H. A. (1977), Transmission-line properties of a strip on a dielectric sheet on a plane, IEEE Tran. Microwave Theory Tech., Vol. MTT-25, No. 8, 631-647, Aug.

[18] Fadhel, Y. A., and Sayidmarie, K. H. (2012), A Novel UWB Impedance Matching for Planar Circular Monopole Antenna Via Meandering the Microstrip Feed Line. Proceedings of ISAP2012 (pp. 539-542), Nagoya, Japan, 25-28 October. 